\title{
Musculoskeletal pain and new-onset poor physical function in elderly survivors of a natural disaster: a longitudinal study after the great East Japan earthquake
}

Yutaka Yabe ${ }^{1}$, Yoshihiro Hagiwara ${ }^{1 *}$, Takuya Sekiguchi $^{1}$, Yumi Sugawara², Masahiro Tsuchiya ${ }^{3}$, Nobuyuki Itaya', Shinichirou Yoshida ${ }^{1}$, Yasuhito Sogi ${ }^{1}$, Toshihisa Yano ${ }^{1}$, Takahiro Onoki ${ }^{1}$, Ichiro Tsuji ${ }^{2}$ and Eiji Itoi ${ }^{1}$

\begin{abstract}
Background: Functional disability is a significant problem after natural disasters. Musculoskeletal pain is reported to increase after disasters, which can cause functional disability among survivors. However, the effects of musculoskeletal pain on functional decline after natural disasters are unclear. The present study aimed to examine the association between musculoskeletal pain and new-onset poor physical function among elderly survivors after the Great East Japan Earthquake.
\end{abstract}

Methods: A longitudinal study was conducted on survivors aged $\geq 65$ years at three and 4 years after the Great East Japan Earthquake. A total of 747 persons were included in this study. Physical function was assessed using the Kihon Checklist. New-onset poor physical function was defined as low physical function not present at 3 years but present at 4 years after the disaster. Knee, hand or foot, low back, shoulder, and neck pain was assessed using a self-reported questionnaire and was defined as musculoskeletal pain. Musculoskeletal pain at 3 years after the disaster was categorized according to the number of pain regions $(0,1, \geq 2)$. Multiple logistic regression analyses were performed to calculate the odds ratio (OR) and $95 \%$ confidence interval $(95 \% \mathrm{Cl})$ for new-onset poor physical function due to musculoskeletal pain.

Results: The incidence of new-onset poor physical function was $14.9 \%$. New-onset poor physical function was significantly associated with musculoskeletal pain. Compared with "O" musculoskeletal pain region, the adjusted ORs $(95 \% \mathrm{Cl})$ were $1.39(0.75-2.58)$ and $2.69(1.52-4.77)$ in "1" and " $\geq 2$ " musculoskeletal pain regions, respectively ( $p$ for trend $=0.003$ ).

Conclusions: Musculoskeletal pain is associated with new-onset poor physical function among elderly survivors after the Great East Japan Earthquake. Monitoring musculoskeletal pain is important to prevent physical function decline after natural disasters.

Keywords: Great East Japan earthquake, Musculoskeletal pain, Natural disaster, Physically disabled, Survivor

\footnotetext{
* Correspondence: hagi@med.tohoku.ac.jp

${ }^{1}$ Department of Orthopaedic Surgery, Tohoku University School of Medicine,

2-1 Seiryo-machi, Aoba-ku, Sendai, Miyagi 980-8574, Japan

Full list of author information is available at the end of the article
}

(c) The Author(s). 2019 Open Access This article is distributed under the terms of the Creative Commons Attribution 4.0 International License (http://creativecommons.org/licenses/by/4.0/), which permits unrestricted use, distribution, and reproduction in any medium, provided you give appropriate credit to the original author(s) and the source, provide a link to the Creative Commons license, and indicate if changes were made. The Creative Commons Public Domain Dedication waiver (http://creativecommons.org/publicdomain/zero/1.0/) applies to the data made available in this article, unless otherwise stated. 


\section{Background}

Functional disability is a significant problem after natural disasters, especially among elderly survivors [1]. The Great East Japan Earthquake (GEJE) and tsunami destroyed the northeast coastal region of Japan in 2011. Due to this serious disaster, approximately 18,500 people died or went missing and 400,000 buildings were destroyed [2]. Reconstruction after disasters of this magnitude takes a significant amount of time; 73,000 survivors continue to take refuge from their hometowns and 13,000 people have lived in prefabricated temporary houses for at least 7 years after the GEJE [3]. Tomata et al., in a longitudinal study after the GEJE, reported that the incidence of functional disability was higher in the disaster areas than in non-disaster areas [4]. Preventing functional decline is an important issue after natural disasters and should be considered even during the disaster recovery period. The environmental habitat changed and many evacuees lost connections with their local communities after the GEJE $[1,5]$. Because older survivors are more vulnerable to these changes, they have had fewer opportunities to go out into the community. Many have become homebound [6, 7], which is generally considered a predictor of functional decline [8]. Furthermore, some authors have reported other factors related to functional disability after the GEJE. Survivors living in temporary housing have limited physical activity, which can lead to functional decline [7]. The rate of psychological distress was reported to increase after the GEJE [9], which was associated with functional disability in older survivors [10]. Higher rates of musculoskeletal pain after the GEJE have also been reported [11-13], which can cause functional disability in survivors. However, the effect of musculoskeletal pain on functional decline after natural disasters has not yet been reported.

The present study aimed to examine the association between musculoskeletal pain and new-onset poor physical function among elderly survivors in the recovery period after the GEJE.

\section{Methods}

\section{Participants}

A longitudinal study was conducted on GEJE survivors living in seriously damaged disaster areas, including Ogatsu and Oshika districts in Ishinomaki City and Wakabayashi Ward in Sendai City, Miyagi Prefecture. We analyzed the data of surveys conducted at three and 4 years after the disaster. The surveys were examined every 6 months starting at 3 months after the GEJE using a self-reported questionnaire. The first study was conducted with residents registered in the Residential Registry of Ogatsu and Oshika districts and residents living in prefabricated houses in Wakabayashi Ward. For 3 years after the disaster, survivors (aged 18 years or over) who were registered in the Residential Registry of Ogatsu and Oshika districts and who participated in the previous survey in the Wakabayashi Ward were recruited $(n=6396)$. Altogether, there were $2853(44.6 \%)$ participants. Among those, 1400 were aged 65 years and over. We excluded participants who already had poor physical function $(n=474)$ or for whom data on physical function were missing $(n=29)$. Study participants were followed up at 4 years after the disaster. The follow-up rate in this period was $85.1 \%$ (763/897); 16 persons were excluded due to missing data on physical function. Finally, 747 persons were analyzed in this study (Fig. 1).

\section{Outcome variables}

Physical function was assessed using the physical function score from the Kihon Checklist (KCL), which is a self-reported questionnaire consisting of five yes/no questions. New-onset poor physical function was defined as poor physical function that was absent at 3 years but present at 4 years after the disaster. The questions were as follows: "Can you climb stairs without holding onto a handrail or wall?," "Can you get up from a chair without grabbing something?," "Are you able to walk for about 15 minutes?," "Have you fallen in the past year?," and "Are you very worried about falling?" [14]. Each negative response received one point, and poor physical function was defined by a score of $\geq 3 / 5$ in the physical function category on the KCL $[14,15]$.

\section{Main predictor}

Musculoskeletal pain at 4 years after the disaster was evaluated using self-reported questionnaires based on the Comprehensive Survey of Living Conditions [3]. The questions included: "Have you had symptoms in the last few days? If yes, please place a check mark next to all your symptoms." The examples of choices were palpitations, dizziness, diarrhea, gastric pain, and musculoskeletal symptoms such as knee, hand or foot, low back, shoulder, and neck pain [16]. Among those, knee, hand or foot, low back, shoulder, and neck pain was defined as musculoskeletal pain [17]. Furthermore, musculoskeletal pain was categorized according to the number of pain regions $(0,1$, and $\geq 2)[12,18]$.

\section{Covariates}

The following variables were considered as covariates according to a previous report [13]: sex, age, body mass index, living areas, smoking habits, drinking habits, chronic conditions (hypertension, diabetes mellitus, myocardial infarction, and cerebral stroke), working status, walking time per day, living environment, subjective economic hardship, psychological distress, sleep disturbance, and social isolation at 3 years after the disaster. Psychological distress, sleep disturbance, and social 


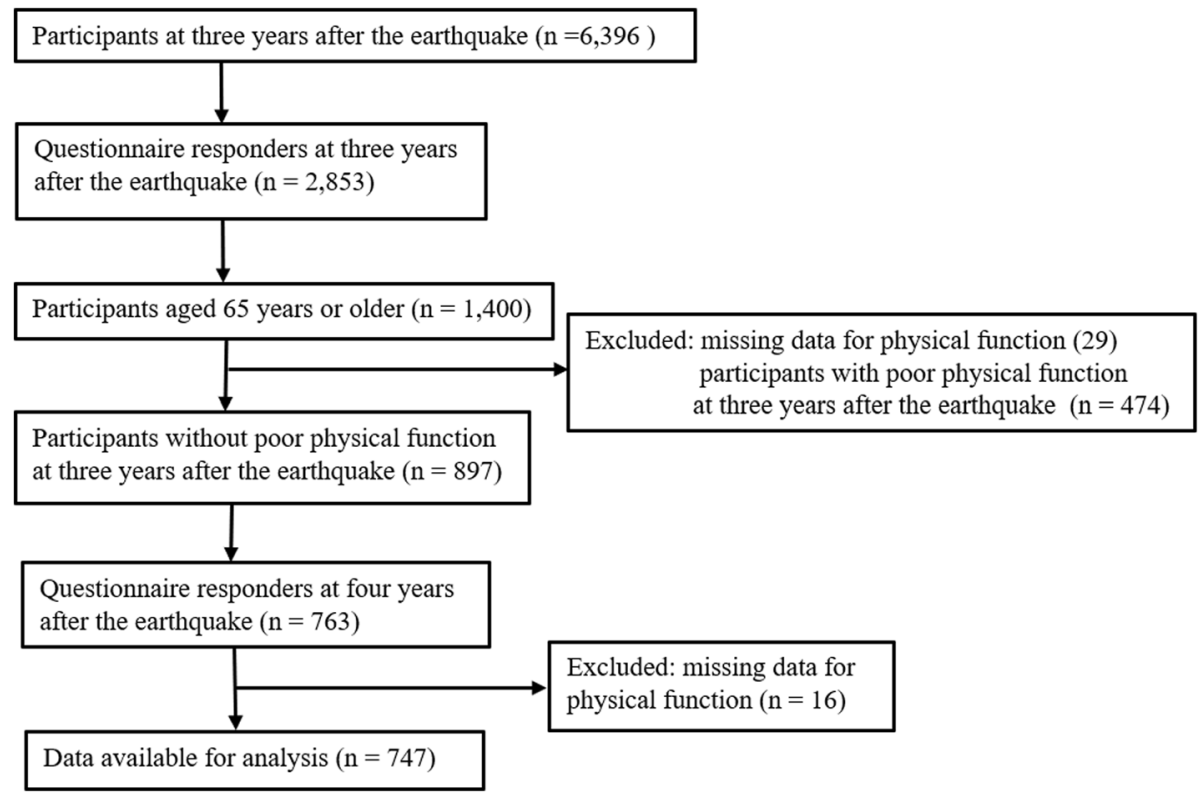

Fig. 1 Flowchart of the present analysis

isolation were assessed and defined as a score $\geq 10 / 24$ on the Kessler Psychological Distress Scale [19], $\geq 6 / 24$ on the Athens Insomnia Scale [20], and $<12 / 30$ on the Lubben Social Network Scale [21], respectively.

\section{Statistical analysis}

Variables are presented as frequencies and percentages (\%). Crude and multiple logistic regression analyses were performed to calculate odds ratios (ORs) and 95\% confidence intervals (95\% CIs) for new-onset poor physical function according to musculoskeletal pain at 3 years after the disaster. Variables used in the analysis were sex, age $(<75$ or $\geq 75$ years), body mass index $(<18.5$, 18.5-24.9, $\geq 25$, or unknown), living areas (Ogatsu, Oshika, or Wakabayashi), smoking habits (non-smoking, smoking, or unknown), drinking habits (non-drinking, $<45.6 \mathrm{~g}$ of alcohol/day, $\geq 45.6 \mathrm{~g}$ of alcohol/day, or unknown), chronic conditions (absence or presence of hypertension, diabetes mellitus, myocardial infarction, and cerebral stroke), working status (unemployed, employed, or unknown), and walking time per day $(<0.5 \mathrm{~h}, 0.5$ to $<1 \mathrm{~h}, \geq 1 \mathrm{~h}$, or unknown) (Model 1). Furthermore, variables related to disasters, such as living environment (same house as before the GEJE, prefabricated house, new house, others, or unknown), subjective economic hardship (normal, a little bit hard, hard, very hard, or unknown), psychological distress (absence, presence, or unknown), sleep disturbance (absence, presence, or unknown), and social isolation (absence, presence, or unknown), were added (Model 2). The ORs and 95\% CIs for new-onset poor physical function according to each musculoskeletal pain region were also evaluated. Moreover, we divided the participants into two subgroups according to age $(<75[n=456]$, or $\geq 75[n=291]$ years $)$, and ORs and 95\% CIs for new-onset poor physical function were assessed in the same manner. SPSS version 24.0 (SPSS Japan Inc., Tokyo, Japan) was used for all analyses and differences at $p<0.05$ were considered statistically significant.

\section{Results}

The participants' baseline characteristics are presented in Table 1. Of the 747 participants analyzed, 489 (65.5\%), 126 (16.9\%), and 132 (17.7\%) had "0," "1," and " $\geq 2$ " musculoskeletal pain regions, respectively (Table 1). New-onset poor physical function had an incidence rate of 14.9\% (111/ 747) and was significantly associated with musculoskeletal pain. Compared with "0" musculoskeletal pain region, the adjusted ORs (95\% CI) were $1.49(0.83-2.65)$ and 2.62 $(1.55-4.42)$ in " 1 " and " $\geq 2$ " musculoskeletal pain regions, respectively, in Model 1 ( $\mathrm{p}$ for trend $=0.001$ ) and were 1.39 $(0.75-2.58)$ and $2.69(1.52-4.77)$ in " 1 " and " $\geq 2$ " musculoskeletal pain regions, respectively, in Model 2 ( $\mathrm{p}$ for trend = 0.003) (Table 2). For each musculoskeletal pain region, new-onset poor physical function was associated with knee and hand or foot pain, but not with low back, shoulder, and neck pain. The adjusted ORs (95\% CI) for new-onset poor physical function were 2.51 (1.43-4.40) for knee pain, 2.60 (1.44-4.71) for hand or foot pain, $1.61(0.94-2.78)$ for low back pain, $1.77(0.78-4.04)$ for shoulder pain, and 1.50 (0.81-2.78) for neck pain (Table 3).

In the stratified analyses, new-onset poor physical function was associated with the presence of musculoskeletal pain in both age groups. Compared with "0" pain region, the adjusted ORs (95\% CI) for new-onset poor physical function were 2.63 (1.04-6.63) for "1" pain region 
Table 1 Baseline characteristics of the participants according to the number of musculoskeletal pain sites

\begin{tabular}{|c|c|c|c|c|c|}
\hline & & Number of & loskeletal pa & $n(\%)$ & \\
\hline & & Total & 0 & 1 & $\geq 2$ \\
\hline & & 747 & 489 & 126 & 132 \\
\hline Sex & Male & $382(51.1)$ & $266(54.4)$ & $54(42.9)$ & $62(47.0)$ \\
\hline & Female & $365(48.9)$ & $223(45.6)$ & $72(57.1)$ & $70(53.0)$ \\
\hline Age & $<75$ & $456(61.0)$ & $305(62.4)$ & $68(54.0)$ & $83(62.9)$ \\
\hline & $\geq 75$ & 291 (39.0) & 184 (37.6) & $58(46.0)$ & 49 (37.1) \\
\hline $\mathrm{BMI}^{\mathrm{a}}$ & $<18.5$ & $18(2.4)$ & $13(2.7)$ & $3(2.4)$ & $2(1.5)$ \\
\hline & $18.5-24.9$ & $426(57.0)$ & $290(59.3)$ & $71(56.3)$ & $65(49.2)$ \\
\hline & $\geq 25$ & $279(37.3)$ & 174 (35.6) & $44(34.9)$ & $61(46.2)$ \\
\hline Living area & Ogatsu & $349(46.7)$ & $236(48.3)$ & $53(42.1)$ & $60(45.5)$ \\
\hline & Oshika & $274(36.7)$ & $180(36.8)$ & $50(39.7)$ & 44 (33.3) \\
\hline & Wakabayashi & $124(16.6)$ & $73(14.9)$ & $23(18.3)$ & $28(21.2)$ \\
\hline Smoking habits ${ }^{a}$ & Non-smoking & 602 (80.6) & 394 (80.6) & $103(81.7)$ & 105 (79.5) \\
\hline & Smoking & $80(10.7)$ & $54(11.0)$ & $10(7.9)$ & $16(12.1)$ \\
\hline Drinking habits ${ }^{a}$ & Non-drinking & $430(57.6)$ & $278(56.9)$ & 79 (62.7) & $73(55.3)$ \\
\hline & $<45.6 \mathrm{~g}$ of alcohol/day ${ }^{\mathrm{b}}$ & $161(21.6)$ & 101 (20.7) & $25(19.8)$ & $35(26.5)$ \\
\hline & $\geq 45.6 \mathrm{~g}$ of alcohol/day ${ }^{\mathrm{b}}$ & $52(7.0)$ & $41(8.4)$ & $4(3.2)$ & $7(5.3)$ \\
\hline Chronic conditions & Hypertension & $423(56.6)$ & $260(53.2)$ & $71(56.3)$ & $92(69.7)$ \\
\hline & Diabetes mellitus & $97(13.0)$ & $58(11.9)$ & $16(12.7)$ & $23(17.4)$ \\
\hline & Myocardial infarction & $71(9.5)$ & $38(7.8)$ & $12(9.5)$ & $21(15.9)$ \\
\hline & Cerebral stroke & $8(1.1)$ & $3(0.6)$ & $2(1.6)$ & $3(2.3)$ \\
\hline Working status ${ }^{a}$ & Unemployed & $522(69.9)$ & $341(69.7)$ & $91(72.2)$ & $90(68.2)$ \\
\hline & Employed & $202(27.0)$ & $133(27.2)$ & $31(24.6)$ & $38(28.8)$ \\
\hline Walking time/day ${ }^{a}$ & $\geq 1 \mathrm{~h}$ & $205(27.4)$ & $153(31.3)$ & $29(23.0)$ & $23(17.4)$ \\
\hline & 0.5 to $<1 \mathrm{~h}$ & $30(44.2)$ & $218(44.6)$ & $56(44.4)$ & $56(42.4)$ \\
\hline & $<0.5 \mathrm{~h}$ & $198(26.5)$ & $108(22.1)$ & $40(31.7)$ & $50(37.9)$ \\
\hline Living environment $^{a}$ & Same house as before the GEJE & $219(29.3)$ & $145(29.7)$ & $43(34.1)$ & $31(23.5)$ \\
\hline & Prefabricated house & $295(39.5)$ & $190(38.9)$ & $52(41.3)$ & $53(40.2)$ \\
\hline & New house & 109 (14.6) & $70(14.3)$ & $12(9.5)$ & $27(20.5)$ \\
\hline & Others & $123(16.5)$ & $83(17.0)$ & $19(15.1)$ & $21(15.9)$ \\
\hline Subjective economic hardship ${ }^{a}$ & Normal & $372(49.8)$ & $262(53.6)$ & $46(36.5)$ & $64(48.5)$ \\
\hline & A little bit hard & $206(27.6)$ & $132(27.0)$ & $40(31.7)$ & $34(25.8)$ \\
\hline & Hard & $115(15.4)$ & $60(12.3)$ & $35(27.8)$ & $20(15.2)$ \\
\hline & Very hard & $34(4.6)$ & $16(3.3)$ & $4(3.2)$ & $14(10.6)$ \\
\hline Psychological distress $^{a}$ & Absence & $651(87.1)$ & $442(90.4)$ & 99 (78.6) & $110(83.3)$ \\
\hline & Presence & $61(8.2)$ & $25(5.1)$ & $17(13.5)$ & $19(14.4)$ \\
\hline Sleep disturbance ${ }^{a}$ & Absence & $552(73.9)$ & $401(82.0)$ & $82(65.1)$ & $69(52.3)$ \\
\hline & Presence & $185(24.8)$ & $80(16.4)$ & $43(34.1)$ & $62(47.0)$ \\
\hline Social isolation ${ }^{a}$ & Absence & $579(77.5)$ & $383(78.3)$ & $95(75.4)$ & $101(76.5)$ \\
\hline & Presence & $164(22.0)$ & $102(20.9)$ & $31(24.6)$ & $31(23.5)$ \\
\hline
\end{tabular}

${ }^{a}$ Because each item has a limited number of respondents, the actual number is not necessarily in accordance with the total.

b $22.8 \mathrm{~g}$ of alcohol amount to $1 \mathrm{go}$ or traditional unit of sake $(180 \mathrm{ml})$, which also approximates to two glasses of wine (200 $\mathrm{ml})$, or beer (500 $\mathrm{ml})$ in terms of alcohol content.

categorical variables are presented as numbers and percentage (\%). 
Table $\mathbf{2}$ Influence of musculoskeletal pain on new-onset poor physical function

\begin{tabular}{|c|c|c|c|c|c|}
\hline & \multicolumn{5}{|c|}{ Number of musculoskeletal pain sites } \\
\hline & total & 0 & 1 & $\geq 2$ & P for trend \\
\hline Participants & 747 & 489 & 126 & 132 & \\
\hline New-onset poor physical function, n (\%) & $111(14.9)$ & $54(11.0)$ & $22(17.5)$ & $35(26.5)$ & \\
\hline Crude OR (95\% Cl) & & 1 & $1.70(0.99-2.92)$ & $2.91(1.80-4.69)$ & $<0.001$ \\
\hline Model 1 OR (95\% Cl) & & 1 & $1.49(0.83-2.65)$ & $2.62(1.55-4.42)$ & 0.001 \\
\hline Model 2 OR (95\% Cl) & & 1 & $1.39(0.75-2.58)$ & $2.69(1.52-4.77)$ & 0.003 \\
\hline
\end{tabular}

and 2.74 (1.16-6.48) for " $\geq 2$ " pain regions in the age $<75$ group ( $\mathrm{p}$ for trend $=0.031$ ) and were $1.06(0.40-2.81$ ) for "1" pain region and $2.99(1.28-6.96)$ for " $\geq 2$ " pain regions in the age $\geq 75$ group ( $p$ for trend $=0.029$ ) (Table 4 ).

Adjusted for sex, age, body mass index, living area, smoking habits, drinking habits, complications, working status, and walking time (Model1). Additionally, adjusted for living status, subjective economic hardship, psychological distress, sleep disturbance, and social isolation (Model 2).

OR Odds Ratio, CI Confidence Interval.

Adjusted for sex, age, body mass index, living area, smoking habits, drinking habits, chronic conditions, working status, walking time, living status, subjective economic hardship, psychological distress, sleep disturbance, and social isolation.

$O R$ odds ratio, $C I$ confidence interval.

Adjusted for sex, body mass index, living area, smoking habits, drinking habits, chronic conditions, working status, walking time, living status, subjective economic hardship, psychological distress, sleep disturbance, and social isolation.

$O R$ odds ratio, $C I$ confidence interval.

\section{Discussion}

This study showed that musculoskeletal pain is associated with new-onset poor physical function among elderly survivors in the recovery period of the GEJE. There have been some reports of functional disabilities after natural disasters $[1,4,6,10,14]$. Some factors related to disasters, such as living in temporary housing [14] and psychological distress [10], are reported to be associated with functional decline; nonetheless, to our knowledge, this is the first study to show that musculoskeletal pain led to poor physical function after a natural disaster. Some authors have reported an association between musculoskeletal pain and physical function in community-dwelling elderly [18, 22, 23]. Pain induced by musculoskeletal disorders, such as osteoarthritis and low back pain, limits physical function [23]. Musculoskeletal pain also reduces the ability to perform physical activities and causes dis-use that can result in muscle weakness, reduced joint range of motion, and reflex inhibition of skeletal muscles that can lead to gait instability or falls $[18,22]$. Some authors have shown that multi-site pain is associated with functional disability among the elderly [22, 24]. Furthermore, Eggermont

Table 3 Influence of each musculoskeletal pain on new-onset poor physical function

\begin{tabular}{|c|c|c|c|c|}
\hline & & absence & presence & $P$ value \\
\hline \multirow[t]{3}{*}{ Knee pain } & Participants & 641 & 106 & \\
\hline & Crude OR (95\% Cl) & 1 & $2.73(1.68-4.42)$ & $<0.001$ \\
\hline & Adjusted OR (95\% Cl) & 1 & $2.51(1.43-4.40)$ & 0.001 \\
\hline \multirow[t]{3}{*}{ Hand or foot pain } & Participants & 653 & 94 & \\
\hline & Crude OR (95\% Cl) & 1 & $2.73(1.65-4.51)$ & $<0.001$ \\
\hline & Adjusted OR (95\% Cl) & 1 & $2.60(1.44-4.71)$ & 0.002 \\
\hline \multirow[t]{3}{*}{ Low back pain } & Participants & 617 & 130 & \\
\hline & Crude OR (95\% Cl) & 1 & $1.99(1.24-3.18)$ & 0.004 \\
\hline & Adjusted OR (95\% Cl) & 1 & $1.61(0.94-2.78)$ & 0.085 \\
\hline \multirow[t]{3}{*}{ Shoulder pain } & Participants & 704 & 43 & \\
\hline & Crude OR (95\% Cl) & 1 & $2.08(1.01-4.25)$ & 0.046 \\
\hline & Adjusted OR (95\% Cl) & 1 & $1.77(0.78-4.04)$ & 0.175 \\
\hline \multirow[t]{3}{*}{ Neck pain } & Participants & 642 & 105 & \\
\hline & Crude OR (95\% Cl) & 1 & $1.77(1.06-2.95)$ & 0.03 \\
\hline & Adjusted OR (95\% Cl) & 1 & $1.50(0.81-2.78)$ & 0.20 \\
\hline
\end{tabular}


Table 4 Stratified analysis for each age group

\begin{tabular}{|c|c|c|c|c|c|}
\hline & \multicolumn{5}{|c|}{ Number of musculoskeletal pain sites } \\
\hline & total & 0 & 1 & $\geq 2$ & $P$ for trend \\
\hline \multicolumn{6}{|l|}{ Age $<75$} \\
\hline Participants & 456 & 305 & 68 & 83 & \\
\hline New-onset poor physical function, n (\%) & $48(10.5)$ & $21(6.9)$ & $11(16.2)$ & $16(19.3)$ & \\
\hline Crude OR (95\% Cl) & & 1 & $2.61(1.19-5.71)$ & $3.23(1.60-6.52)$ & 0.002 \\
\hline Adjusted OR (95\% Cl) & & 1 & $2.63(1.04-6.63)$ & $2.74(1.16-6.48)$ & 0.031 \\
\hline \multicolumn{6}{|l|}{ Age $\geq 75$} \\
\hline Participants & 291 & 184 & 58 & 49 & \\
\hline New-onset poor physical function, n (\%) & $63(21.6)$ & $33(17.9)$ & $11(19.0)$ & $19(38.8)$ & \\
\hline Crude OR $(95 \% \mathrm{Cl})$ & & 1 & $1.07(0.50-2.28)$ & $2.90(1.46-5.76)$ & 0.008 \\
\hline Adjusted OR (95\% Cl) & & 1 & $1.06(0.40-2.81)$ & $2.99(1.28-6.96)$ & 0.029 \\
\hline
\end{tabular}

et al. reported that the association between musculoskeletal pain and functional disability became stronger as the number of pain sites increased [25]. This is similar to our results. Natural disasters deprive numerous lives and properties from survivors, changing their living status and economic condition $[5,13]$ and resulting in psychological distress [17], sleep disturbance [12], and social isolation [21]. These conditions can have negative effects on the functional condition of survivors. Nevertheless, the association between musculoskeletal pain and new-onset physical function was similar after adjustment for these factors. Preceding musculoskeletal pain is associated with functional decline, even in special circumstances such as natural disasters. After the GEJE, psychological distress, sleep disturbance, and economic hardship increased among survivors $[9,26]$. These factors are thought to lead to increased musculoskeletal pain $[13,27-30]$. Approximately $34.5 \%$ of survivors had musculoskeletal pain and more than half of them had multi-site pain in this study. Functional disabilities increased after the GEJE [4] and increased musculoskeletal pain could be one of the main reasons for it. Furthermore, the association between musculoskeletal pain and new-onset poor physical function was different according to each pain region; in particular, it was significant for knee and hand or foot pain, but not for low back, shoulder, and neck pain. It is possible that this result depended on the specific questionnaire used in assessing physical function in this study. Physical function scores on the KCL focused on the importance of walking ability and falls [14], which can be easily affected by lower extremity pain. Leveille et al. reported that only foot pain was related to an increased risk of falls in site-specific pain [31]. Yiengprugsawan et al. showed that the impact of site-specific pain on activities of daily living related to mobility was stronger with knee pain than with low back pain [24]. Lower extremity pain by itself was considered to affect the onset of poor physical function among survivors by lowering walking ability or increasing the risk of falls.

The prevalence of new-onset poor physical function among survivors aged $\geq 75$ years was approximately twice the rate of that among survivors aged $<75$ years. Functional decline was more common in older survivors, which is in accordance with the former report after the GEJE [1]. In the age $<75$ group, both single-site and multi-site musculoskeletal pains were associated with new-onset poor physical function. On the other hand, the association was significant when the number of pain sites was $\geq 2$ in the age $\geq 75$ group. Because aging is associated with structural and functional changes [32], various factors affect functional decline in the elderly, which may minimize the effect of single-site musculoskeletal pain on physical function among survivors aged $\geq 75$ years. In both groups, musculoskeletal pain was associated with new-onset poor physical function. It is important to take note of musculoskeletal pain, particularly multi-site pain, to prevent physical function decline among survivors of natural disasters. Hasegawa et al. reported that a community-based exercise class was effective for reducing musculoskeletal pain [33]. It is important for elderly survivors to maintain physical activity levels to reduce musculoskeletal pain, which can prevent physical function decline.

\section{Limitations}

This study has several limitations. First, the questionnaires and informed consent forms were mailed and the response rate was not high. The people who responded might have been in better health than those who did not respond, which could affect the results. Second, musculoskeletal pain and physical function were assessed in only two periods and changes in other periods were unknown. Third, musculoskeletal pain was assessed using 
self-reported questionnaires based on the Comprehensive Survey of Living Conditions. Although this survey is widely accepted in Japan, the reliability and validity of this method were not evaluated in this study. Furthermore, the questionnaires included five pain sites but did not include other musculoskeletal pains such as hip or elbow pain. Because these pains could have also led to physical function decline, this might have affected the results. In addition, the degree of pain was not assessed. Finally, this study did not include a control group, because the disaster struck a vast area of Japan.

\section{Conclusion}

Musculoskeletal pain is associated with new-onset poor physical function among elderly survivors in the recovery period after the GEJE. Monitoring musculoskeletal pain is important to prevent physical function decline after natural disasters.

\section{Abbreviations}

95\% Cl: 95\% confidence interval; GEJE: Great East Japan Earthquake KCL: Kihon Checklist; OR: Odds ratio

\section{Acknowledgements}

Not applicable.

\section{Authors' contributions}

YY, YH, and IT contributed to study design. YS1, MT, NI, SY, YS2, TY, and TO were responsible for data collection and supervised the study. TS and YY performed statistical analysis. YY, YH, and El wrote the manuscript. YS1, MT, and IT aided in analyzing the data and drafting the manuscript. All authors have read and approved the manuscript.

\section{Funding}

This work was supported by Health Sciences Research Grants (H24, 25-KenkiShintei-002 [Fukkou]) from the Ministry of Health, Labour and Welfare of Japan. The funder approved the design of the study but had no role in the collection, analysis, and interpretation of the data, or in writing the manuscript.

\section{Availability of data and materials}

All relevant data are contained in this article.

\section{Ethics approval and consent to participate}

The study protocol was reviewed and approved by the Ethics Committee of Tohoku University Graduate School of Medicine (approval number: 201192). Written informed consent was obtained from all participants.

\section{Consent for publication}

Not applicable.

\section{Competing interests}

The authors declare no conflict of interest.

\section{Author details}

'Department of Orthopaedic Surgery, Tohoku University School of Medicine, 2-1 Seiryo-machi, Aoba-ku, Sendai, Miyagi 980-8574, Japan. ²Division of Epidemiology, Department of Health Informatics and Public Health, Tohoku University Graduate School of Public Health, 2-1 Seiryo-machi, Aoba-ku Sendai, Miyagi 980-8575, Japan. ${ }^{3}$ Department of Nursing, Faculty of Health Science, Tohoku Fukushi University, 1-8-1 Kunimi, Aoba-ku, Sendai, Miyagi 981-8522, Japan.
Received: 31 May 2019 Accepted: 13 September 2019

Published online: 17 October 2019

\section{References}

1. Kuroda Y, Iwasa H, Orui M, Moriyama N, Suemoto CK, Yashiro C, Matsuda K, Yasumura S. Risk factor for incident functional disability and the effect of a preventive exercise program: a 4-year prospective cohort study of older survivors from the great East Japan earthquake and nuclear disaster. Int J Environ Res Public Health. 2018;15(7):E1430.

2. Ishigaki A, Higashi H, Sakamoto T, Shibahara S. The great East-Japan earthquake and devastating tsunami: an update and lessons from the past great earthquakes in Japan since 1923. Tohoku J Exp Med. 2013; 229(4):287-99.

3. Yabe $Y$, Hagiwara $Y$, Sekiguchi T, Sugawara $Y$, Tsuchiya M, Koide M, Itaya N, Yoshida S, Sogi Y, Yano T, et al. Sleep disturbance is associated with new onset and continuation of lower back pain: a longitudinal study among survivors of the great East Japan earthquake. Tohoku J Exp Med. 2018; 246(1):9-14.

4. Tomata $Y$, Suzuki $Y$, Kawado M, Yamada H, Murakami $Y$, Mieno MN, Shibata Y, Ojima T, Hashimoto S, Tsuji I. Long-term impact of the 2011 great East Japan earthquake and tsunami on functional disability among older people: a 3-year longitudinal comparison of disability prevalence among Japanese municipalities. Soc Sci Med. 2015;147:296-9.

5. Moriyama N, Urabe Y, Onoda S, Maeda N, Oikawa T. Effect of residence in temporary housing after the great East Japan earthquake on the physical activity and quality of life of older survivors. Disaster Med Public Health Prep. 2017;11(6):701-10.

6. Greiner C, Ono K, Otoguro C, Chiba K, Ota N. Intervention for the maintenance and improvement of physical function and quality of life among elderly disaster victims of the great East Japan earthquake and tsunami. Appl Nurs Res. 2016;31:154-9.

7. Yoshimura E, Ishikawa-Takata K, Murakami H, Tsuboyama-Kasaoka N, Tsubota-Utsugi M, Miyachi M, Yokoyama Y, Sakata K, Kobayashi S, Ogawa A, et al. Relationships between social factors and physical activity among elderly survivors of the great East Japan earthquake: a cross-sectional study. BMC Geriatr. 2016;16:30.

8. Fujiwara Y, Nishi M, Fukaya T, Hasebe M, Nonaka K, Koike T, Suzuki H, Murayama Y, Saito M, Kobayashi E. Synergistic or independent impacts of low frequency of going outside the home and social isolation on functional decline: a 4-year prospective study of urban Japanese older adults. Geriatr Gerontol Int. 2017:17(3):500-8.

9. Yokoyama Y, Otsuka K, Kawakami N, Kobayashi S, Ogawa A, Tannno K, Onoda T, Yaegashi Y, Sakata K. Mental health and related factors after the great East Japan earthquake and tsunami. PLoS One. 2014;9(7):e102497.

10. Tanji F, Sugawara $Y$, Tomata $Y$, Watanabe T, Sugiyama $K$, Kaiho $Y$, Tomita H, Tsuji I. Psychological distress and the incident risk of functional disability in elderly survivors after the great East Japan earthquake. J Affect Disord. 2017; 221:145-50

11. Yabuki S, Ouchi K, Kikuchi S, Konno S. Pain, quality of life and activity in aged evacuees living in temporary housing after the great East Japan earthquake of 11 march 2011: a cross-sectional study in Minamisoma City, Fukushima prefecture. BMC Musculoskelet Disord. 2015:16:246.

12. Yabe $Y$, Hagiwara $Y$, Sekiguchi $T$, Sugawara $Y$, Tsuchiya M, Koide M, Itaya N, Yoshida S, Sogi Y, Yano T, et al. Higher incidence of sleep disturbance among survivors with musculoskeletal pain after the great East Japan earthquake: a prospective study. Tohoku J Exp Med. 2018;244(1):25-32.

13. Sekiguchi T, Hagiwara Y, Sugawara $Y$, Tomata $Y$, Tanji F, Watanabe T, Yabe $Y$,

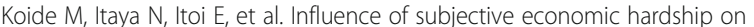
new onset of neck pain (so-called: katakori) in the chronic phase of the great East Japan earthquake: a prospective cohort study. J Orthop Sci. 2018; 23(5):758-64.

14. Ito K, Tomata Y, Kogure M, Sugawara Y, Watanabe T, Asaka T, Tsuji I. Housing type after the great East Japan earthquake and loss of motor function in elderly victims: a prospective observational study. BMJ Open. 2016:6(11):e012760.

15. Fukutomi E, Okumiya K, Wada T, Sakamoto R, Ishimoto $Y$, Kimura Y, Chen WL, Imai H, Kasahara Y, Fujisawa MJG, et al. Relationships between each category of 25-item frailty risk assessment (Kihon checklist) and newly certified older adults under long-term care insurance: a 24-month follow-up study in a rural community in Japan. Geriatr Gerontol Int. 2015;15(7):864-71. 
16. Hagiwara Y, Sekiguchi T, Sugawara Y, Yabe Y, Koide M, Itaya N, Yoshida S, Sogi Y, Tsuchiya M, Tsuji I, et al. Association between sleep disturbance and new-onset subjective shoulder pain in survivors of the great East Japan earthquake: a prospective cohort study in Miyagi prefecture. Tohoku J Exp Med. 2017;242:193-201.

17. Yabe $Y$, Hagiwara $Y$, Sekiguchi $T$, Sugawara $Y$, Tsuchiya M, Koide M, Itaya $N$, Yoshida S, Sogi Y, Yano T, et al. Musculoskeletal pain is associated with new-onset psychological distress in survivors of the great East Japan earthquake. Disaster Med Public Health Prep. 2018;13(2):295-300.

18. Sawa R, Doi T, Misu S, Saito T, Sugimoto T, Murata S, Asai T, Yamada M, Ono $R$. The severity and number of musculoskeletal pain associated with gait in community-dwelling elderly individuals. Gait Posture. 2017;54:242-7.

19. Suzuki Y, Fukasawa M, Obara A, Kim Y. Mental health distress and related factors among prefectural public servants seven months after the great East Japan earthquake. J Epidemiol. 2014;24(4):287-94.

20. Soldatos CR, Dikeos DG, Paparrigopoulos TJ. Athens insomnia scale: validation of an instrument based on ICD-10 criteria. J Psychosom Res. 2000; 48(6):555-60.

21. Sone T, Nakaya N, Sugawara Y, Tomata Y, Watanabe T, Tsuji I. Longitudinal association between time-varying social isolation and psychological distress after the great East Japan earthquake. Soc Sci Med. 2016;152:96-101.

22. Leveille SG, Jones RN, Kiely DK, Hausdorff JM, Shmerling RH, Guralnik JM, Kiel DP, Lipsitz LA, Bean JF. Chronic musculoskeletal pain and the occurrence of falls in an older population. JAMA. 2009:302(20):2214-21.

23. Marley J, Tully MA, Porter-Armstrong A, Bunting B, O'Hanlon J, Atkins L, Howes S, McDonough SM. The effectiveness of interventions aimed at increasing physical activity in adults with persistent musculoskeletal pain: a systematic review and meta-analysis. BMC Musculoskelet Disord. 2017;18(1):482

24. Yiengprugsawan V, Steptoe A. Impacts of persistent general and sitespecific pain on activities of daily living and physical performance: a prospective analysis of the English longitudinal study of ageing. Geriatr Gerontol Int. 2018;18(7):1051-7.

25. Eggermont LH, Leveille SG, Shi L, Kiely DK, Shmerling RH, Jones RN, Guralnik $J M$, Bean JF. Pain characteristics associated with the onset of disability in older adults: the maintenance of balance, independent living, intellect, and zest in the elderly Boston study. J Am Geriatr Soc. 2014;62(6):1007-16.

26. Matsumoto S, Yamaoka K, Inoue M, Muto S. Social ties may play a critical role in mitigating sleep difficulties in disaster-affected communities: a crosssectional study in the Ishinomaki area, Japan. Sleep. 2014:37(1):137-45.

27. Hagiwara Y, Sekiguchi T, Sugawara Y, Yabe Y, Koide M, Itaya N, Yoshida S, Sogi Y, Tsuchiya M, Tsuji I, et al. Association between sleep disturbance and new-onset subjective knee pain in great East Japan earthquake survivors: a prospective cohort study in the Miyagi prefecture. J Orthop Sci. 2018;23(2):334-40.

28. Tsuji T, Matsudaira K, Sato H, Vietri J. The impact of depression among chronic low back pain patients in Japan. BMC Musculoskelet Disord. 2016;17(1):447.

29. Yabe Y, Hagiwara Y, Sekiguchi T, Sugawara Y, Sato M, Kanazawa K, Koide M, Itaya N, Tsuchiya M, Tsuji I, et al. Influence of living environment and subjective economic hardship on new-onset of low back pain for survivors of the great East Japan earthquake. J Orthop Sci. 2017;22(1):43-9.

30. Hagiwara Y, Sekiguchi T, Yabe Y, Sugawara Y, Watanabe T, Kanazawa K, Koide M, Itaya N, Tsuchiya M, Tsuji I, et al. Living status, economic hardship and sleep disturbance were associated with subjective shoulder pain in survivors of the great East Japan earthquake: a cross sectional study. J Orthop Sci. 2017;22(3):442-6.

31. Leveille SG, Bean J, Bandeen-Roche K, Jones R, Hochberg M, Guralnik JM. Musculoskeletal pain and risk for falls in older disabled women living in the community. J Am Geriatr Soc. 2002;50(4):671-8.

32. Blyth FM, Noguchi N. Chronic musculoskeletal pain and its impact on older people. Best Pract Res Clin Rheumatol. 2017;31(2):160-8.

33. Hasegawa M, Yamazaki S, Kimura M, Nakano K, Yasumura S. Communitybased exercise program reduces chronic knee pain in elderly Japanese women at high risk of requiring long-term care: a non-randomized controlled trial. Geriatr Gerontol Int. 2013;13(1):167-74.

\section{Publisher's Note}

Springer Nature remains neutral with regard to jurisdictional claims in published maps and institutional affiliations.

\section{Ready to submit your research? Choose BMC and benefit from:}

- fast, convenient online submission

- thorough peer review by experienced researchers in your field

- rapid publication on acceptance

- support for research data, including large and complex data types

- gold Open Access which fosters wider collaboration and increased citations

- maximum visibility for your research: over $100 \mathrm{M}$ website views per year

At $\mathrm{BMC}$, research is always in progress.

Learn more biomedcentral.com/submissions 